\title{
Thermal Durability of Thermal Barrier Coatings in Furnace Cyclic Thermal Fatigue Test: Effects of Purity and Monoclinic Phase in Feedstock Powder
}

\author{
Hyun-Myung Park*, Soo-Hyk Jun*, Guanlin Lyu*, Yeon-Gil Jung*,', \\ Byung-Il Yan**, and Kwang-Yong Park** \\ ${ }^{*}$ School of Materials Science and Engineering, Changwon National University, Changwon 51140, Korea \\ *Doosan Heavy Industries \& Construction, Changwon 51711, Korea
}

(Received September 13, 2018; Revised October 25, 2018; Accepted October 25, 2018)

\begin{abstract}
The effects of the purity and monoclinic phase of feedstock powder on the thermal durability of thermal barrier coatings (TBC) were investigated through cyclic thermal exposure. Bond and top coats were deposited by high velocity oxygen fuel method using $\mathrm{Ni}$-Co based feedstock powder and air plasma spray method using three kinds of yttria-stabilized zirconia with different purity and monoclinic phase content, respectively. Furnace cyclic thermal fatigue test was performed to investigate the thermal fatigue behavior and thermal durability of TBCs. TBCs with high purity powder showed better sintering resistance and less thickness in the thermally grown oxide layer. The thermal durability was found to strongly depend on the content of monoclinic phase and the porosity in the top coat; the best thermal fatigue behavior and thermal durability were in the TBC prepared with high purity powder without monoclinic phase.
\end{abstract}

Key words : Thermal barrier coating, Feedstock powder, Monoclinic phase, Purity, Thermal durability

\section{Introduction}

$\mathrm{T}$ hermal barrier coatings (TBC) are applied for the protection of components from high temperature gases during the operation of gas turbines for power generation and aircraft. Generally, the TBC system is composed of a top coat and a bond coat. The top coat is a ceramic layer that provides thermal barrier functionality to the high temperature components of the gas turbine; the bond coat provides not only oxidation and corrosion resistance to the substrate but also increases the adhesive strength between the top coat and base material, where generally the $\operatorname{MCrAlY}(\mathrm{M}=$ $\mathrm{Ni}$ and/or Co) material is used. ${ }^{1)}$

The application of TBCs is consistently in demand as they reduce the surface temperature of high temperature gas turbine components by $100-150^{\circ} \mathrm{C}$, increasing the turbine inlet temperature, which leads to fuel efficiency improvement. ${ }^{2-7)}$ However, the $7-8 \mathrm{wt} \%$ yttria stabilized zirconia (78YSZ) applied to the conventional top coat is limited for application in operational environments of $1200^{\circ} \mathrm{C}$ or higher by the resintering and phase transition. ${ }^{8,9)}$ Thus, improvement of the thermal barrier performance, improvement of sintering resistance, and attaining of phase stability of the top coat are required to enhance the temperature capability of the superalloys used as base materials of high tempera-

\footnotetext{
${ }^{\dagger}$ Corresponding author : Yeon-Gil Jung

E-mail : jungyg@changwon.ac.kr

Tel : +82-55-213-3712 Fax : +82-55-262-6486
}

ture components. In this area, studies of low thermal conductivity zirconate materials have been actively pursued. ${ }^{10-12)}$ However, compared to conventional 7-8YSZ, ${ }^{13-15)}$ low thermal conductivity zirconate materials have relatively low thermal expansion coefficients (8YSZ: $10.5-11.5 \times 10^{-6} \mathrm{~K}^{-1}$, Yb-Gd-YSZ: $\left.9-10 \times 10^{-6} \mathrm{~K}^{-1}, \mathrm{La}_{2} \mathrm{Zr}_{2} \mathrm{O}_{7}: 9.1-9.7 \times 10^{-6} \quad \mathrm{~K}^{-1}\right)$, along with relatively low mechanical properties (Yb-Gd-YSZ fracture toughness: $\sim 1.25 \mathrm{MPa} \cdot \mathrm{m}^{1 / 2}, \mathrm{La}_{2} \mathrm{Zr}_{2} \mathrm{O}_{7}$ fracture toughness: $\sim 1.1 \mathrm{MPa} \cdot \mathrm{m}^{1 / 2}$, 8YSZ: $\left.\sim 2.23 \mathrm{MPa} \cdot \mathrm{m}^{1 / 2}\right) .{ }^{13,16)}$ Due to these thermal and mechanical properties, there are difficulties in applying zirconate as TBC material for gas turbines, despite their outstanding phase stability and sintering resistance, and low thermal conductivity. In order to overcome these disadvantages, various studies on microstructural design, compositional design, and composites are being carried out. ${ }^{11,12)}$

Meanwhile, the concept of decreasing the quantity of impurities (silica, alumina, etc.) contained in conventional yttria stabilized zirconia (7-8YSZ) was presented as a method of improving the sintering resistance and phase stability. ${ }^{17}{ }^{18)}$ As a part of studies on ceramic phase stability, studies on feedstock powder without monoclinic phase are in progress. ${ }^{19)}$ However, as mentioned above, due to their thermal and mechanical properties, zirconate materials are limited in their application to high temperature components. Although research on the effects of TBCs composed of materials with high purity and phase stability on the thermal durability have been conducted individually, a comprehensive study that considers both factors together has yet to 
be conducted.

The furnace cyclic test (FCT) is a conventional method of thermal durability evaluation that assesses the interfacial stability and thermal stability through the thermal expansion coefficient (8YSZ: $10.5-11.5 \times 10^{-6} \mathrm{~K}^{-1}$, NiCrAlY bond coat: $15.0 \times 10^{-6} \mathrm{~K}^{-1}$ ) difference between the top coat and bond coat by conducting repeated heating and cooling in a high temperature isothermal environment. ${ }^{14-16)}$ However, FCT heats the coating layer as well as the base material to high temperatures (the base material temperature increases), so the actual gas turbine operation conditions are not satisfied and the lifetime of the TBC is decreased. However, the furnace cyclic thermal fatigue test (FCTF) used in this study cools the base material temperature to $950^{\circ} \mathrm{C}$ during the test, so the effect of the base material on the lifetime evaluation of the TBC can be minimized and the thermal durability can be assessed under conditions similar to those of the actual gas turbine operation environment.

Therefore, in this study, various feedstock powders (general purity YSZ, high purity YSZ with monoclinic phase, high purity YSZ without monoclinic phase) were used in the air-plasma spray (APS) method to form the top coat layer, and FCTF testing was carried out at $1100^{\circ} \mathrm{C}$. The effect of the feedstock powder characteristics (purity and whether monoclinic phase is included or not) on the thermal durability of the TBC was investigated by observing microstructure and mechanical property changes, by performing interfacial reaction layer analysis, and by observing phase transformation before and after FCTF testing.

\section{Experimental Procedure}

\subsection{Test Specimen Fabrication}

In this study, Ni-based superalloy (Nimonic 263, with nominal composition of Ni-20Cr-20Co-5.9Mo-0.5Al-2.1Ti0.4Mn-0.3Si-0.06C, in wt\%, ThyssenKrupp VDM, Germany) was used as the base material; the test specimen diameter and thickness were $25.4 \mathrm{~mm}$ and $3 \mathrm{~mm}$, respectively. Grit blasting treatment was performed to allow convenient coating layer formation on the surface of the Ni-based superalloy base material, and CoNiCrAlY powder (Co-29-35Ni-1824Cr-5-11Al-0.1-0.8Y, in wt\%, Oerlikon Metco, Switzerland) was used to fabricate the bond coat using the high velocity oxygen fuel (HVOF) device TAFA JP5000 (Praxair Surface Technology, USA). For the top coat, general purity YSZ $\left(\mathrm{ZrO}_{2}-7-9 \mathrm{Y}_{2} \mathrm{O}_{3}-0.7 \mathrm{SiO}_{2}-0.2 \mathrm{TiO}_{2}-0.2 \mathrm{Al}_{2} \mathrm{O}_{3}-0.2 \mathrm{Fe}_{2} \mathrm{O}_{3}\right.$, in wt\%, Oerlikon Metco, Switzerland), high purity YSZ $\left(\mathrm{ZrO}_{2}\right.$ $7-8 \mathrm{Y}_{2} \mathrm{O}_{3}-0.05 \mathrm{SiO}_{2}-0.05 \mathrm{TiO}_{2}-0.05 \mathrm{Al}_{2} \mathrm{O}_{3}-0.05 \mathrm{Fe}_{2} \mathrm{O}_{3}$, in wt\%, Oerlikon Metco, Switzerland), and high purity YSZ without monoclinic phase and containing $\mathrm{HfO}_{2}$ for mechanical property enhancement $\left(\mathrm{ZrO}_{2}-7-9 \mathrm{Y}_{2} \mathrm{O}_{3}-0.05 \mathrm{Al}_{2} \mathrm{O}_{3}-0.01 \mathrm{Fe}_{2} \mathrm{O}_{3}\right.$ $1.7 \mathrm{HfO}_{2}$, in wt\%, Praxair, USA) were used as the feedstock powders. Table 1 shows the chemical composition, particle size, and whether monoclinic phase is included for each powder or not. ${ }^{20)}$

In order to minimize the effect of the feedstock powder particle size on the microstructure of the top coat, a powder with similar particle size distribution was selected as the feedstock powder, and the particle size distribution was evaluated using a particle sizing analyzer (BECKMAN

Table 1. Composition and Particle Size of Feedstock Powders (a) Substrate (Nimonic 263)

\begin{tabular}{ccccccccccccc}
\hline $\mathrm{Ni}$ & $\mathrm{Co}$ & $\mathrm{Cr}$ & $\mathrm{Mo}$ & $\mathrm{Ti}$ & $\mathrm{Fe}$ & $\mathrm{Mn}$ & $\mathrm{Al}$ & $\mathrm{Si}$ & $\mathrm{Cu}$ & $\mathrm{C}$ & $\mathrm{B}$ & $\mathrm{S}$ \\
\hline \multirow{2}{*}{49} & \multirow{2}{*}{$19-21$} & \multirow{2}{*}{$19-21$} & \multirow{2}{*}{$5.6-6.1$} & \multirow{2}{*}{$1.9-2.4$} & \multirow{2}{*}{ 0.7 Max. 0.6 Max 0.6 Max. 0.4 Max 0.2 Max } & $\begin{array}{c}0.04- \\
0.08\end{array}$ & $\begin{array}{c}0.005 \\
\text { Max }\end{array}$ & $\begin{array}{c}0.007 \\
\text { Max }\end{array}$ \\
\hline
\end{tabular}

(b) Bond coat

\begin{tabular}{ccccccc}
\hline Co & $\mathrm{Ni}$ & $\mathrm{Cr}$ & $\mathrm{Al}$ & $\mathrm{Y}$ & Other $(\max )$ & $\begin{array}{c}\text { Particle Size } \\
\left(\mathrm{d}_{50}, \mu \mathrm{m}\right)\end{array}$ \\
\hline Bal. & $29-35$ & $18-24$ & $5-11$ & $0.1-0.8$ & 1.0 & 24.12 \\
\hline
\end{tabular}

(c) Top coat

\begin{tabular}{cccccccccc}
\hline Powder & $\mathrm{ZrO}_{2}$ & $\mathrm{Y}_{2} \mathrm{O}_{3}$ & $\mathrm{SiO}_{2}$ & $\mathrm{TiO}_{2}$ & $\mathrm{Al}_{2} \mathrm{O}_{3}$ & $\mathrm{Fe}_{2} \mathrm{O}_{3}$ & $\mathrm{HfO}_{2}$ & $\begin{array}{c}\text { Monoclinic } \\
\text { Phase }(\%)\end{array}$ & $\begin{array}{c}\text { Particle Size } \\
\left(\mathrm{d}_{50}, \mu \mathrm{m}\right)\end{array}$ \\
\hline General purity & Balance & $7.0-9.0$ & 0.7 & 0.2 & 0.2 & 0.2 & - & 10 & 61.37 \\
$\begin{array}{c}\text { High purity } \\
\text { High purity }\end{array}$ & Balance & $7.0-8.0$ & 0.05 & 0.05 & 0.05 & 0.05 & - & 10 & 51.62 \\
(Non-monoclinic phase) & Balance & $7.0-9.0$ & 0 & 0 & 0.05 & 0.01 & 1.7 & 0 & 57 \\
\hline
\end{tabular}

Table 2. Spraying Parameters to Prepare Bond and Top Coats

\begin{tabular}{ccccccc}
\hline Item & Gun & Feeding rate & Gun distance & Gun speed & Step distance & Carrier gas \\
\hline Bond coat (HVOF) & DJ2600 & $50 \mathrm{~g} / \mathrm{min}$ & $355 \mathrm{~mm}$ & $1000 \mathrm{~mm} / \mathrm{s}$ & $3 \mathrm{~mm}$ & $\mathrm{~N}_{2}$ \\
Top coat (APS) & $9 \mathrm{MB}$ & $40 \mathrm{~g} / \mathrm{min}$ & $100 \mathrm{~mm}$ & $700 \mathrm{~mm} / \mathrm{s}$ & $\mathrm{mm}$ & $\mathrm{Ar}$ \\
\hline
\end{tabular}



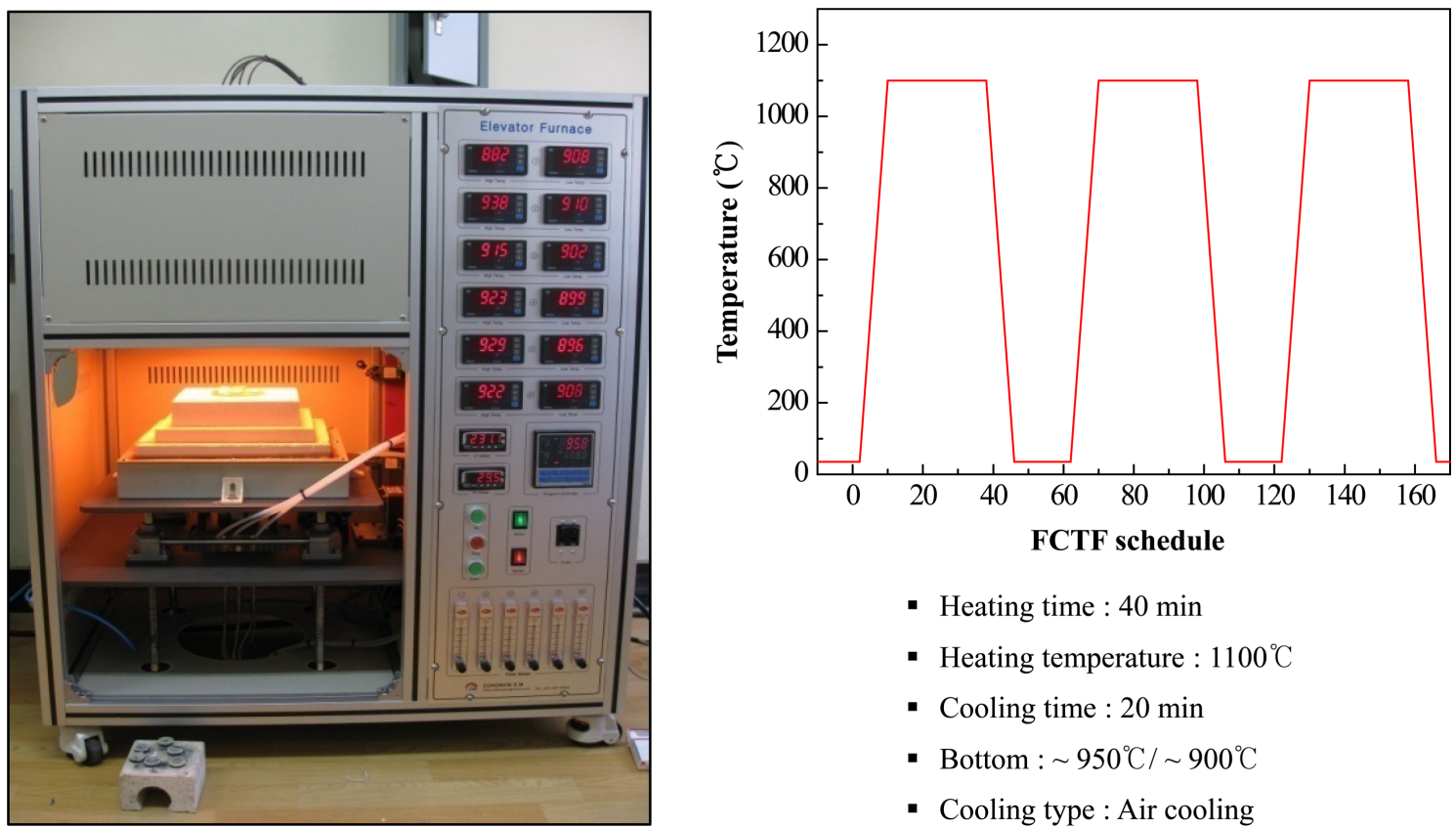

Fig. 1. Test condition and equipment for furnace cyclic thermal fatigue (FCTF) test.

COULTER, Model LS 13 320, America) before fabricating the top coat. For the top coat deposition, the APS method was employed using a $60 \mathrm{~kW}$ plasma spray gun (F4-MB XL) with a $9 \mathrm{~mm}$ nozzle, $9 \mathrm{MC}$ control unit, and Twin-10-C powder feeder (Oerlikon Metco, USA). Table 2 shows the conditions of the bond coat and top coat fabrications.

\subsection{Furnace Cyclic Thermal Fatigue (FCTF)}

FCTF testing was conducted as shown in Fig. 1 to evaluate the thermal durability of specimens with top coats fabricated with the general purity YSZ, high purity YSZ with monoclinic phase, and high purity YSZ without monoclinic phase. The FCTF test was performed for 1429 cycles (30000EOH), where 1 cycle involved 40 minutes of maintenance at $1100^{\circ} \mathrm{C}$ followed by cooling in air for 20 minutes. The test was terminated when coating layer delamination or spallation of approximately $25 \%$ occurred. ${ }^{21)}$ In this study, the equivalent operating hour $(\mathrm{EOH})$, generally used for lifetime assessment of generator gas turbine systems, was employed as the test unit in order to evaluate the thermal durability of the TBC. EOH is a function of the actual operation hour $(\mathrm{AOH})$, calibration coefficient $\left(\Sigma \mathrm{S}_{\mathrm{i}}\right)$, load removal $\left(\Sigma L R_{\mathrm{i}}\right)$, operation time, trial run $\left(\Sigma \mathrm{T}_{\mathrm{i}}\right)$, sudden load change $\left(\Sigma L \mathrm{C}_{\mathrm{i}}\right)$, standby, and fuel operation. ${ }^{22,23)}$ Based on the $\mathrm{EOH}$, the preservation and inspection interval unit is used rather than the actual working time.

$$
\mathrm{EOH}=\mathrm{AOH}+20\left[\Sigma \mathrm{S}_{\mathrm{i}}+\Sigma \mathrm{LR}_{\mathrm{i}}+\Sigma \mathrm{T}_{\mathrm{i}}+\Sigma \mathrm{LC}_{\mathrm{i}}\right] \times \mathrm{F}
$$

Here, $\mathrm{F}$ refers to the fuel coefficient (gas: 1.0). In this study, the testing was carried out by making an estimate using the number of cycles multiplied by 21 for the EOH.

\subsection{Microstructure and Characteristics Evaluation}

In order to analyze the microstructure of the specimens top coat fabricated using general purity YSZ, high purity YSZ with monoclinic phase, and high purity YSZ without monoclinic phase, the specimens were cut, cold mounted using epoxy resin, and mirror polished using silicon carbide abrasive paper and diamond paste of 3 and $1 \mu \mathrm{m}$. The microstructure of the prepared specimens was observed using a scanning electron microscope (SEM, JEOL, Model JSM-5610, Japan), and the hardness and Young's modulus of the coating layer were measured through Vickers hardness experiment (HM-114, Mitutoyo Corp., Japan) and nano-indentation (Nano Indenter XP, MTS Systems Corp., Eden Prairie, USA) analysis.

In order to measure the porosity change before and after FCTF, an image analysis method that measures the ratio of pores in the area of a cross section microstructure image of the top coat was used ${ }^{24,25)}$ the change in monoclinic phase of the specimens before and after the thermal fatigue testing was analyzed using the X-ray diffraction (XRD, PANalytical, X'Pert PRO MPD, Netherlands) analysis method. Energy dispersive X-ray spectroscopy (energy dispersive spectrometer, EDS, Oxford Instruments, Oxford, UK) was used to analyze the composition profile of thermally grown oxide (TGO), and the formation behaviors of TGO $\left(\mathrm{Al}_{2} \mathrm{O}_{3}, \mathrm{Cr}_{2} \mathrm{O}_{3}\right.$, $\mathrm{CoAl}_{2} \mathrm{O}_{4}, \mathrm{CoCr}_{2} \mathrm{O}_{4}, \mathrm{NiAl}_{2} \mathrm{O}_{4}$, etc.) and toxic oxides (Chromia $\left((\mathrm{Cr}, \mathrm{Al})_{2} \mathrm{O}_{3}\right)$, Spinels $\left(\mathrm{Ni}(\mathrm{Cr}, \mathrm{Al})_{2} \mathrm{O}_{4}\right)$ and nickel oxide $(\mathrm{NiO})$, CSN) were compared and analyzed according to the composition change of the feedstock powder for the top coat. ${ }^{26)}$

\section{Results and Discussion}

\subsection{Microstructure}

Figure 2 shows the cross section microstructure of the 

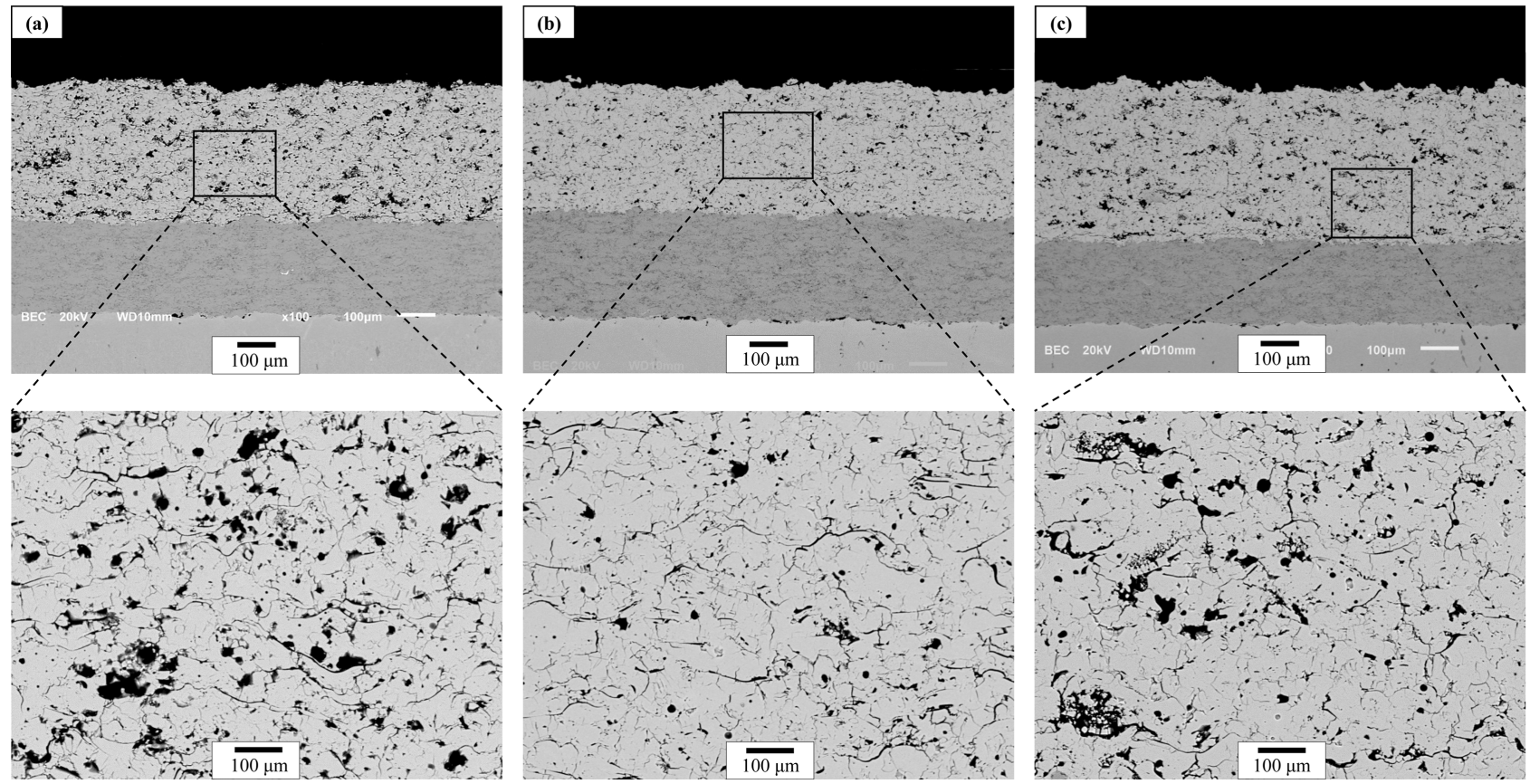

Fig. 2. Microstructure of as-sprayed thermal barrier coatings: (a) general purity YSZ, (b) high purity YSZ with monoclinic phase, and (c) high purity YSZ without monoclinic phase.

coatings formed using general purity YSZ, high purity YSZ with monoclinic phase, and high purity YSZ without monoclinic phase. The top coat and bond coat fabricated for each specimen had thicknesses of $350 \sim 400 \mu \mathrm{m}$ and $150 \sim 200$ $\mu \mathrm{m}$, respectively; through this, it was determined that the effect of the coating layer thickness on the thermal barrier performance was minimized. Also, typical characteristics of pores and splat boundaries for the APS method were identified, while process defects and large fractures that can appear in the coating fabrication process were not observed. Additionally, both interfaces (the top and bond coatings, and the bond coating and substrate) showed sound conditions. The image analysis results showed porosities of $16.1 \%, 9.7 \%$, and $17.0 \%$ for the general purity YSZ, high
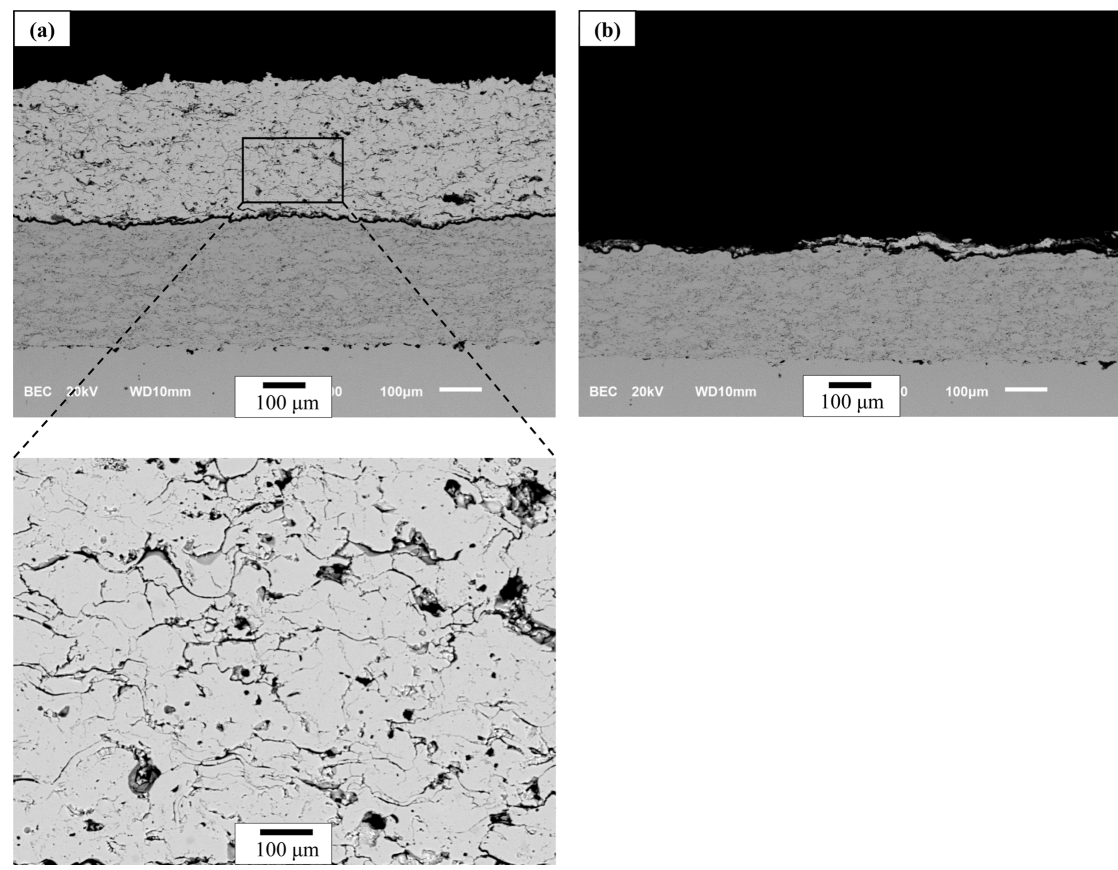

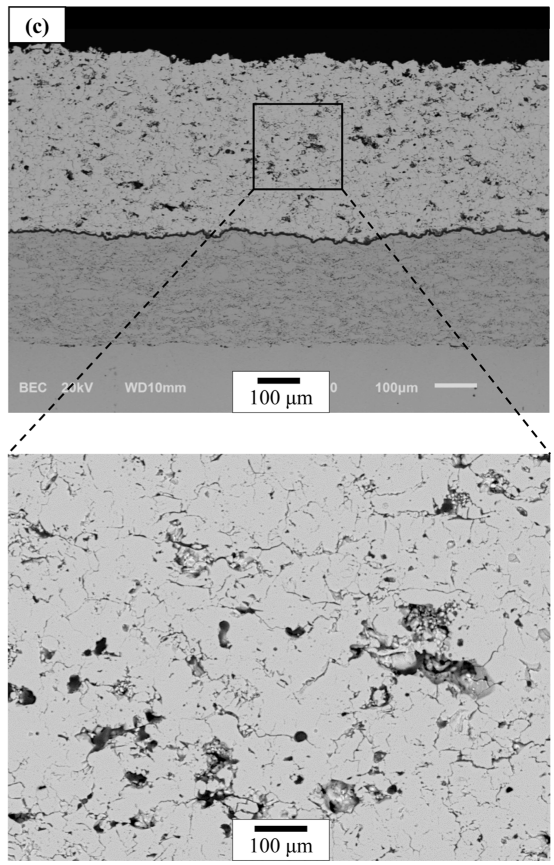

Fig. 3. Microstructure of thermal barrier coatings after FCTF test: (a) general purity YSZ, (b) high purity YSZ with monoclinic phase, and (c) high purity YSZ without monoclinic phase. 
purity YSZ, and high purity YSZ without monoclinic phase, respectively.

\subsection{Thermal Durability}

Figure 3 shows the microstructure of each specimen after FCTF. After the FCTF test (1429 Cycle, around 30,000 $\mathrm{EOH})$, the specimens fabricated using general purity YSZ and high purity YSZ without monoclinic phase showed favorable microstructures with no delamination or failure at the interface between the top coat and bond coat. However, as can be observed in specimen (b) shown in Fig. 3, delamination was found at the interface between the bond coat and top coat for the high purity YSZ specimen.

Although high purity, which is known as having the excellent sintering resistance, should lead to higher thermal durability due to the high porosity from the sintering resistance, the top coat of the specimen fabricated using high purity YSZ with monoclinic phase showed a relatively low porosity, so it was predicted to have a shorter lifetime than the specimens fabricated using general purity YSZ and high purity YSZ without monoclinic phase. This result was due to the high Young's modulus exhibited by the coating, which also had a relatively high density that reduced the mitigation effect of the stress applied due to the difference in the thermal expansion coefficients of the bond coat and top coat during FCTF testing. ${ }^{27-29)}$

The microstructure of TBCs can generally be affected by the feedstock powder particle size and distribution, along with the coating condition. Since all coating layers were fabricated under identical conditions in this study, the microstructure or porosity difference was thought to be affected by the feedstock powder particle size; Fig. 4 shows the particle size and distribution measurement results for each feedstock powder. When compared with the high purity YSZ with monoclinic phase, the general purity YSZ showed a rel- atively high $\mathrm{d}_{50}$ distribution, and the overall particle size for the high purity YSZ without monoclinic phase showed a greater $d_{90}$ (larger particles) distribution compared to the high purity YSZ with monoclinic phase. Through this, it was thought that more pores were formed in the specimens fabricated using general purity YSZ and high purity YSZ without monoclinic phase compared to the specimen fabricated using high purity YSZ with monoclinic phase.

Figure 5 shows the porosity measurement results for the top coatings before and after the FCTF test. The porosities before and after FCTF were $16.1 \%$ and $8.3 \%$ for the general purity YSZ specimen, $9.7 \%$ and $6.1 \%$ for the high purity YSZ specimen with monoclinic phase, and $17.0 \%$ and $11.8 \%$ for the high purity YSZ specimen without monoclinic phase, respectively. So, the porosity changes for general purity YSZ, high purity YSZ with monoclinic phase, and high purity YSZ without monoclinic phase were $7.8 \%, 3.6 \%$, and $5.2 \%$, respectively. In addition, it can be observed in the small amount of change for the high purity YSZ specimen without monoclinic phase, in the porosity change before and after FCTF of the general purity YSZ specimen with a porosity of $16.1 \%$, and in the high purity YSZ specimen without monoclinic phase, which had a porosity of $17.0 \%$, that the high purity YSZ specimen without monoclinic phase had a higher sintering resistance than that of the general purity YSZ specimen. However, the high purity YSZ specimen with monoclinic phase with high density (low porosity) showed a lower thermal durability and shorter lifetime compared to the general purity YSZ specimen. This result was thought to be due to difficulty of effectively releasing the stress produced by the thermal expansion coefficient difference between the base material and the coating layer when the porosity of the top coat is low, which results in the reductions of the thermal durability and lifetime. $^{28)}$

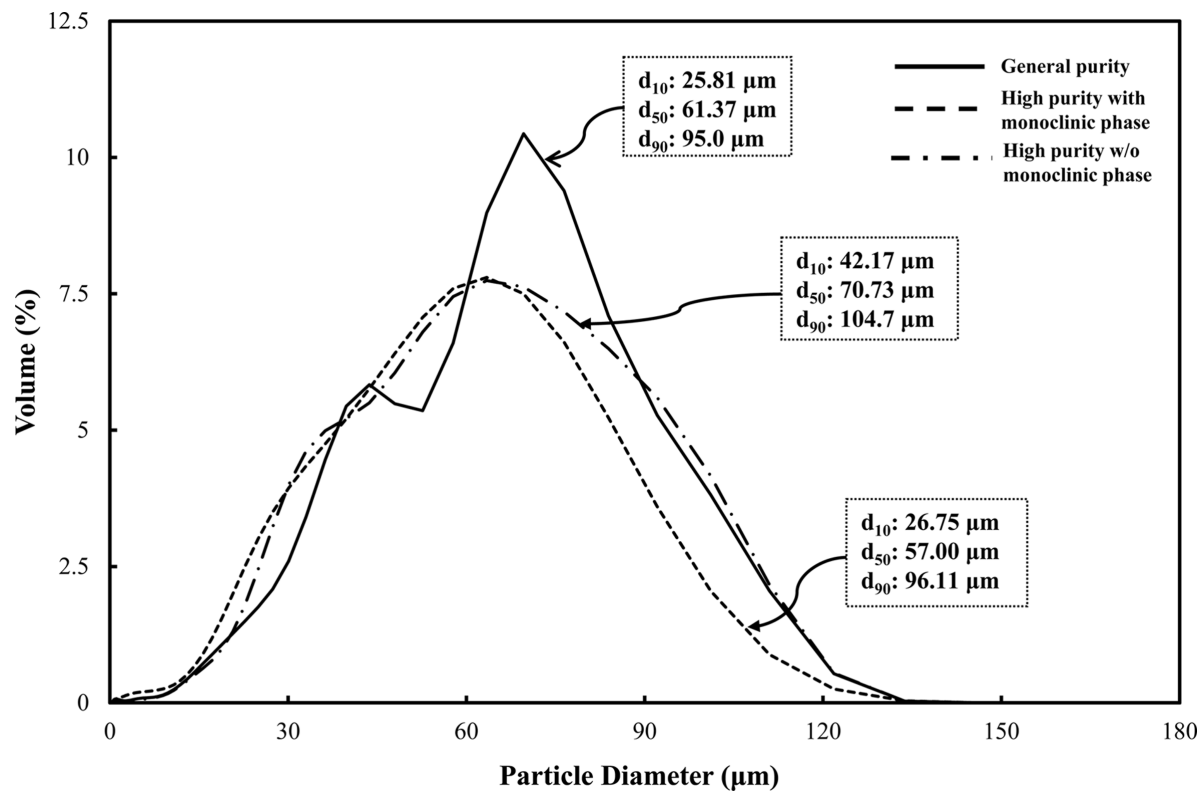

Fig. 4. Particle size and distribution of feedstock powders used in this study. 


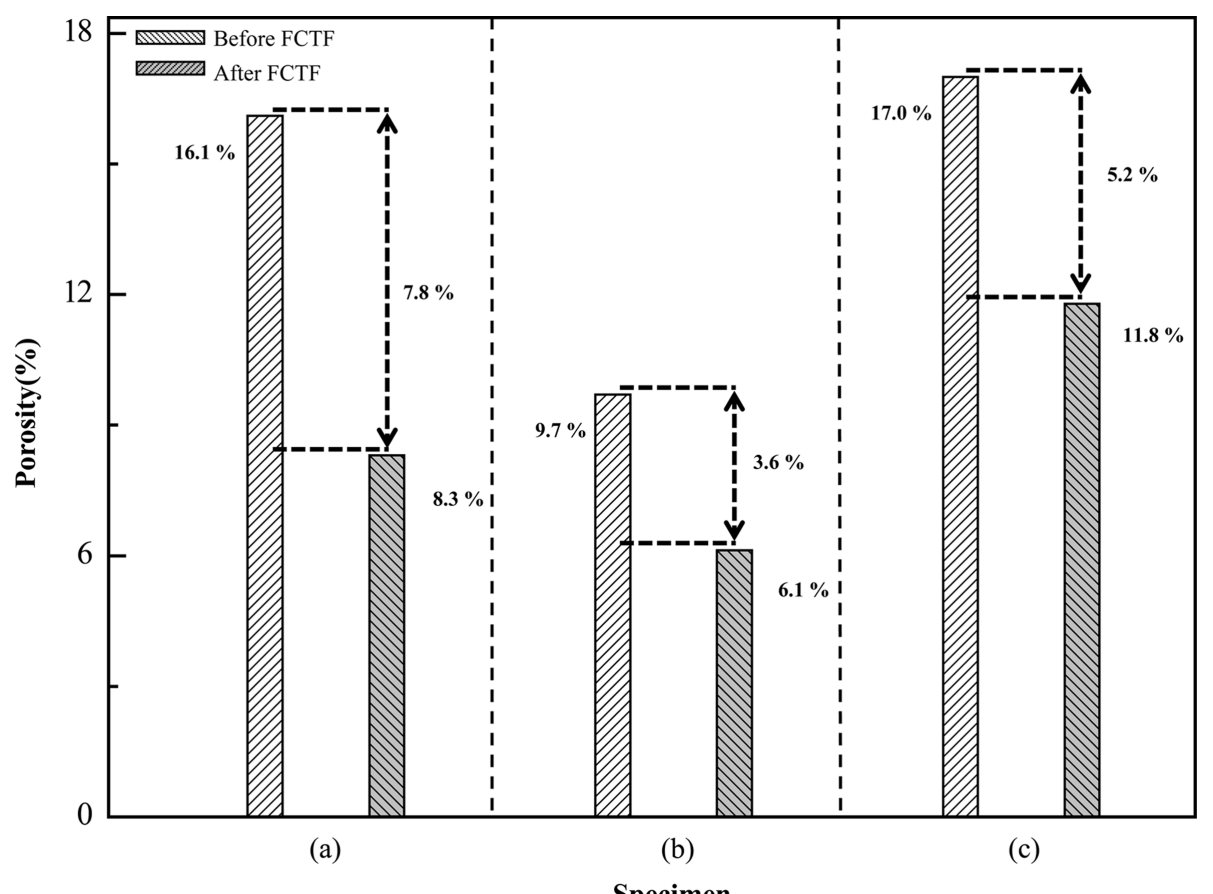

Fig. 5. Porosity of top coats before and after FCTF test: (a) general purity YSZ, (b) high purity YSZ with monoclinic phase, and (c) high purity YSZ without monoclinic phase.

\subsection{Mechanical Properties}

The mechanical properties (hardness and Young's modulus) of the top coat before and after FCTF test for the specimens fabricated according to the purity and monoclinic phase presence of the feedstock powder were evaluated and the results are shown in Fig. 6. First, the Vickers hardness values of the general purity YSZ specimen and high purity YSZ specimen without monoclinic phase before FCTF had similar values of $5.5 \pm 0.5 \mathrm{GPa}$ and $5.5 \pm 0.3 \mathrm{GPa}$, respectively, whereas the high purity YSZ specimen with mono-

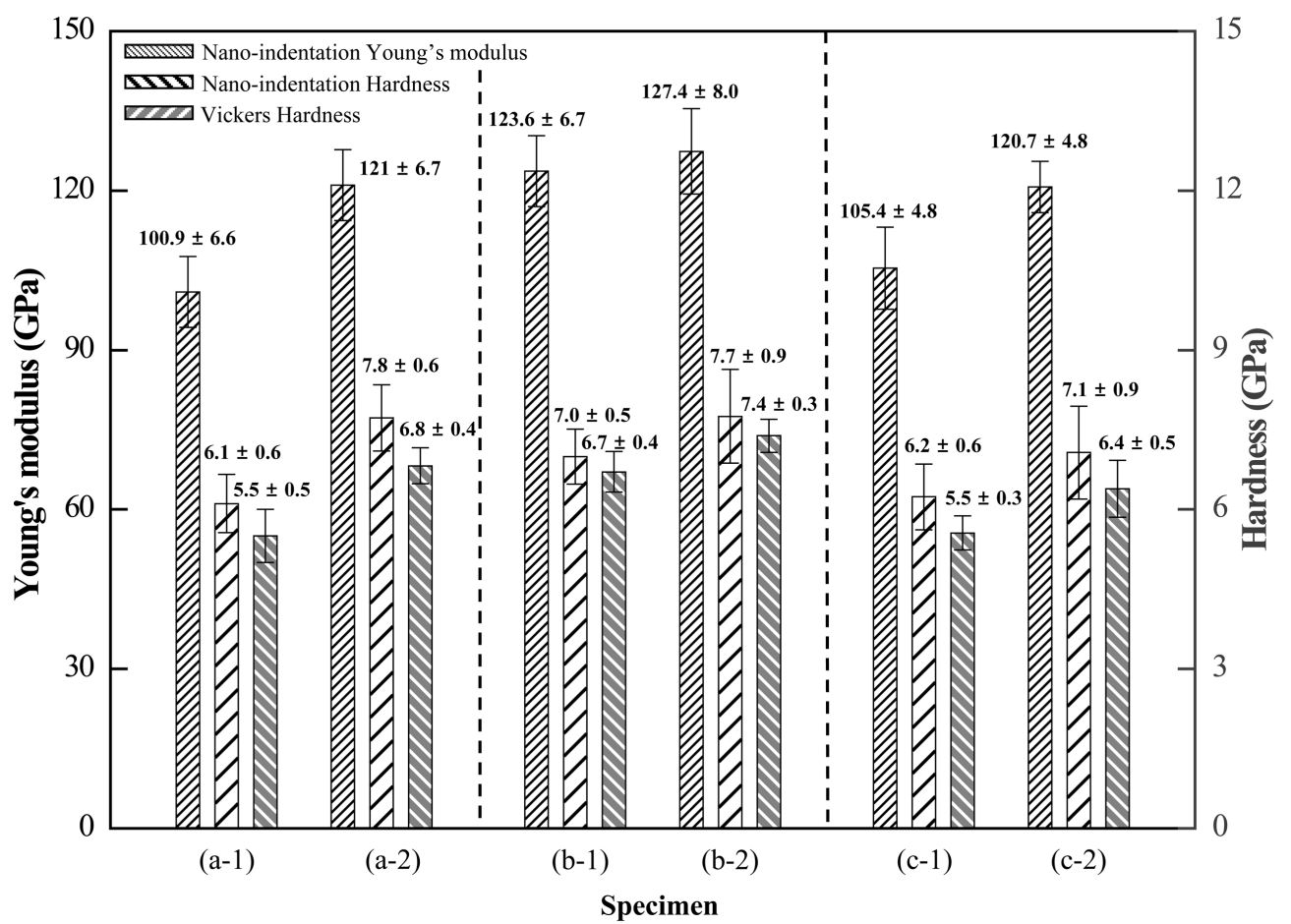

Fig. 6. Mechanical properties of top coats before and after FCTF test: (a) general purity YSZ, (b) high purity YSZ with monoclinic phase, and (c) high purity YSZ without monoclinic phase. Each number indicates values before and after the FCTF test, respectively. 
clinic phase showed a hardness value of $6.7 \pm 0.4 \mathrm{GPa}$, which was slightly higher than those of the other two specimens. After FCTF, the hardness values of the specimens fabricated using the general purity YSZ, high purity YSZ with monoclinic phase, and high purity YSZ without monoclinic phase were $6.8 \pm 0.4 \mathrm{GPa}, 7.4 \pm 0.3 \mathrm{GPa}$, and $6.4 \pm 0.5$ $\mathrm{GPa}$, respectively, which were increases compared to before FCTF. The hardness values, measured before FCTF by using the nano-indentation method, were $6.1 \pm 0.6 \mathrm{GPa}, 7.0$ $\pm 0.5 \mathrm{GPa}$, and $6.2 \pm 0.6 \mathrm{GPa}$, respectively, while the hardness values after FCTF showed increases to $7.8 \pm 0.6 \mathrm{GPa}$, $7.7 \pm 0.9 \mathrm{GPa}$, and $7.1 \pm 0.9 \mathrm{GPa}$, respectively. From the hardness value change before and after FCTF, obtained using the Vickers hardness and nano-indentation measurement methods, it was found that the hardness change of the general purity YSZ specimen was the largest and the hardness changes of the high purity YSZ specimens were the smallest. Although the hardness value changes before and after FCTF for all the specimens were similar, differences were found for the absolute values. The indentation range of the nano-indentation method is smaller than the Vickers indentation range, so the pore or splat boundary contents decreased, resulting in a relatively high hardness value for the nano-indentation test.
The Young's modulus measurement results obtained through the nano-indentation method showed a similar trend, in which the specimen fabricated using high purity YSZ with monoclinic phase showed high values both before and after FCTF, while the general purity YSZ specimen and high purity YSZ specimen without monoclinic phase showed similar measurement values. Similar to the changes of the hardness values, the Young's modulus change of the general purity YSZ specimen after FCTF was the largest. These results reveal that the specimens fabricated with high purity feedstock powder, regardless of the presence of monoclinic phase, exhibited high sintering resistance in comparison to the specimen fabricated using general purity feedstock powder. However, a high Young's modulus decreases the capability of deformation or the stress capability, reducing the thermal durability and lifetime of a TBC. On the other hand, although the sintering resistance of TBCs can be improved by using a high purity powder, it was found that the mechanical property was affected by the porosity according to the feedstock powder particle size and distribution, along with the coating process and method, rather than by the purity of the feedstock powder. Therefore, application of high purity YSZ without monoclinic phase, exhibiting high porosity and outstanding sintering resistance from
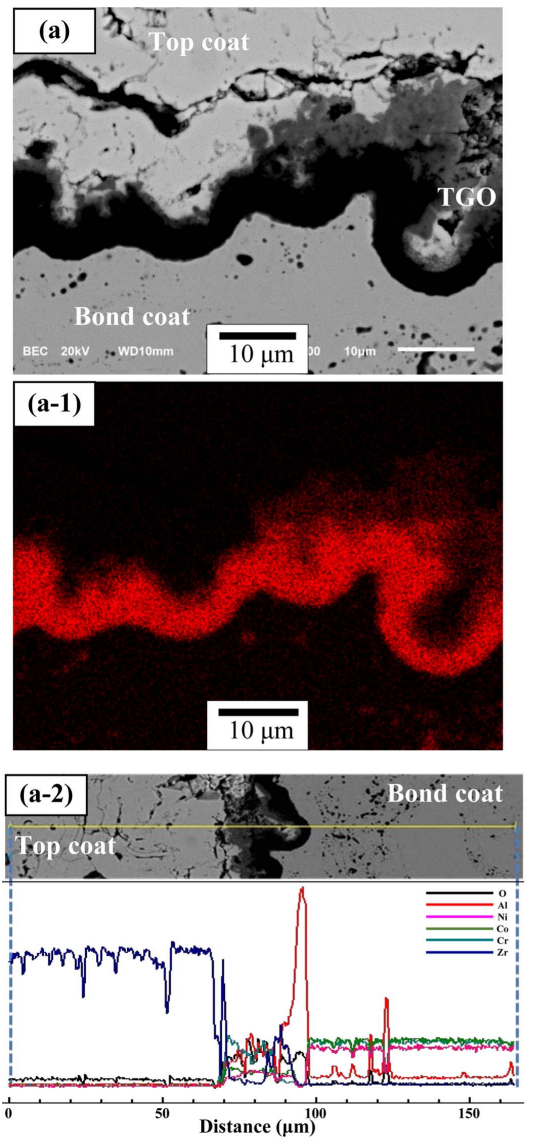
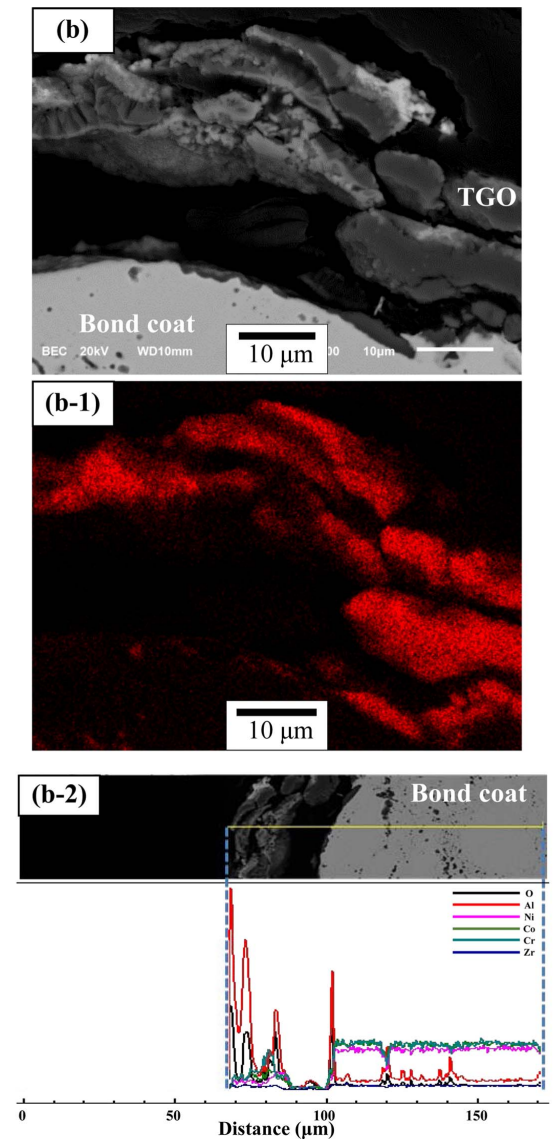
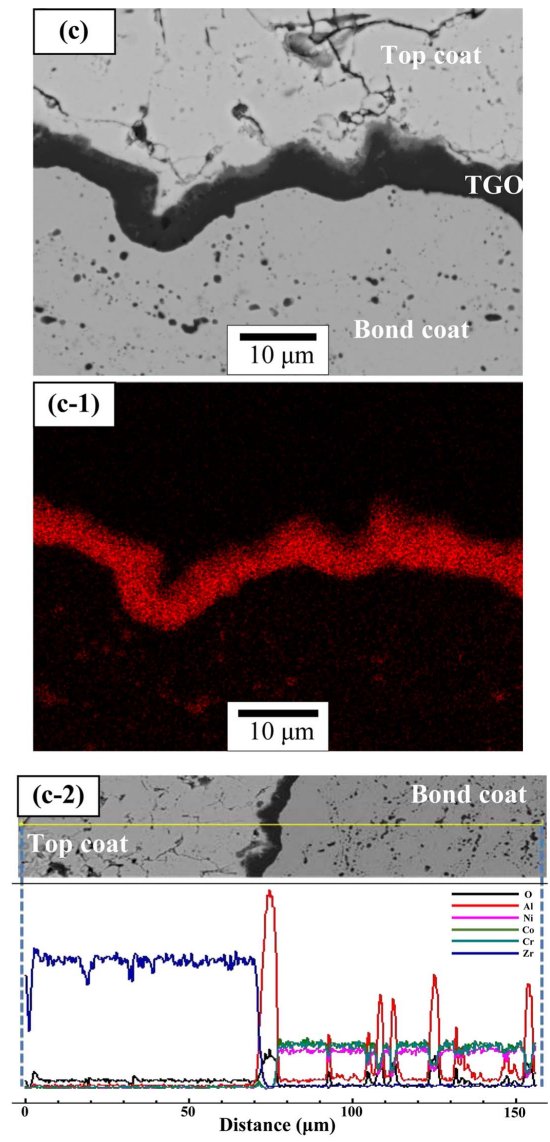

Fig. 7. EDS mapping of each specimen after FCTF test: (a) general purity YSZ, (b) high purity YSZ with monoclinic phase, and (c) high purity YSZ without monoclinic phase. Each number indicates TGO layer at the interface, Al element, and EDS line mapping, respectively. 
FCTF, is expected to increase the stress capability and improve the lifetime of the coating layer. ${ }^{30}$

\subsection{Energy-Dispersive X-ray Spectroscopy (EDS)}

Composition analysis was carried out on a TGO produced in the top coat and bond coat interface before and after FCTF; the results are shown in Fig. 7. For all the specimens, the main components $\mathrm{Al}, \mathrm{Cr}, \mathrm{Co}$, and $\mathrm{Ni}$ of the TGO layer at the specimen interface were observed after FCTF. The TGO thicknesses for the general purity YSZ specimen, high purity YSZ specimen with monoclinic phase, and high purity YSZ specimen without monoclinic phase were $8.5 \pm$ $2.1 \mu \mathrm{m}, 13.5 \pm 4.2 \mu \mathrm{m}$, and $5.5 \pm 1.0 \mu \mathrm{m}$, respectively. The TGO was thickest for the high purity YSZ specimen with monoclinic phase; compared to the general purity YSZ specimen, the TGO growth was the slowest for the high purity YSZ specimen without monoclinic phase. Additionally, it was thought that TGO growth was rapid due to top coat delamination and oxidation for the high purity YSZ specimen with monoclinic phase. When the thermal barrier coating system is exposed to the thermal environment, the formation of TGO at the interface between the top coat and bond coat cannot be avoided, but in order to prevent fracture initiation or delamination of the TBC, the $\alpha-\mathrm{Al}_{2} \mathrm{O}_{3}$ composition, which provides excellent adhesiveness and mechanical properties, has to grow in a slow but uniform manner to prevent initial fracture and delamination of the TBC coating layer. ${ }^{31)}$ When the $\mathrm{Al}$ content decreases in the TGO, such that $\mathrm{Al}_{2} \mathrm{O}_{3}$ growth becomes insufficient, the $\mathrm{Cr}$, $\mathrm{Ni}$, and Co elements bond to the TGO to produce a toxic oxide (CSN). CSN has low mechanical properties (especially fracture toughness) compared to those of $\mathrm{Al}_{2} \mathrm{O}_{3}$, and so fracture of the coating layer is induced. ${ }^{32,33)}$ As can be seen in the magnified microstructures shown in Fig. 7(a), (b), and (c), the oxide scale of both sides can be observed to have formed internally (black: $\mathrm{Al}_{2} \mathrm{O}_{3}$ ) and externally (gray: $\mathrm{Cr}_{2} \mathrm{O}_{3}, \mathrm{NiAl}_{2} \mathrm{O}_{4}$, and other spinel structures). ${ }^{34}$

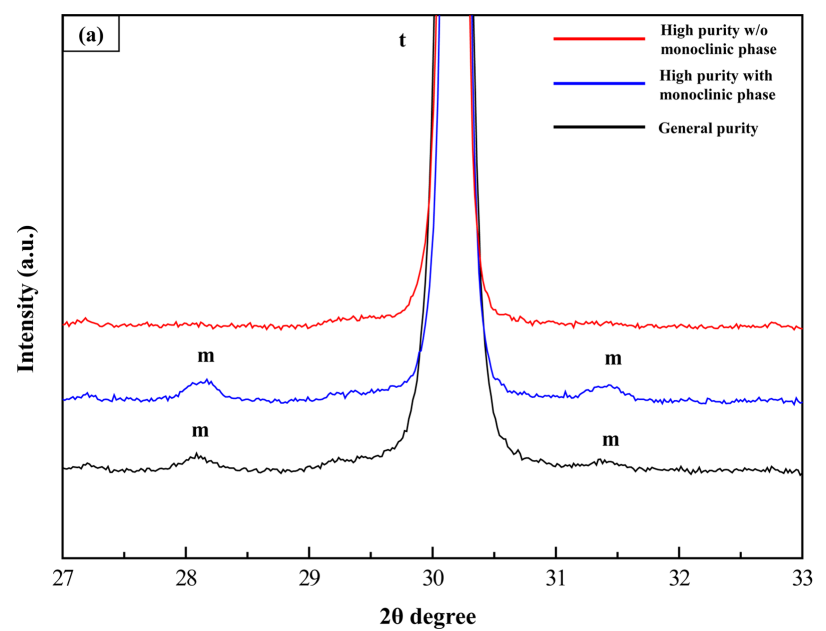

\subsection{X-ray Diffraction}

In order to observe the phase change of the specimens before and after FCTF, or the monoclinic phase peak change, the phase change was analyzed for ranges of $27^{\circ}<$ $2 \theta<28^{\circ}$ and $31^{\circ}<2 \theta<32^{\circ}$; the results obtained are shown in Fig. 8. Generally, the crystalline structure of $\mathrm{ZrO}_{2}$ changes during cooling and the phase transformation to monoclinic phase causes fracture or crack formation at the coating layer due to volume expansion of approximately $4 \% .^{35)}$ Monoclinic phase was observed for the general purity YSZ specimen and high purity YSZ specimen with monoclinic phase before and after FCTF. The specimen fabricated using general purity YSZ containing 10\% monoclinic phase from the feedstock powder, due to impurities, experienced accelerated phase transition after FCTF and showed a trend of increasing monoclinic phase peak strength. For the high purity YSZ specimen with $10 \%$ monoclinic phase, a peak pattern similar to that of general purity YSZ containing $10 \%$ monoclinic phase was observed, but monoclinic phase transition was suppressed by the thermal fatigue due to the higher feedstock powder purity; no significant change in monoclinic phase peak strength was found. However, in the case of the high purity YSZ specimen without monoclinic phase, phase change was not observed before or after FCTF. Through this, phase stability of TBC was determined according to the feedstock powder purity and presence of monoclinic phase. When high purity YSZ powder without monoclinic phase is applied, it is thought that outstanding phase stability and thermal properties will be exhibited in response to the gradually increasing gas turbine operation temperature.

\section{Conclusions}

In this study, the effects of the feedstock powder purity and existence of monoclinic phase on the microstructure, mechanical properties, and thermal durability of thermal barrier coating (TBC) were investigated through furnace

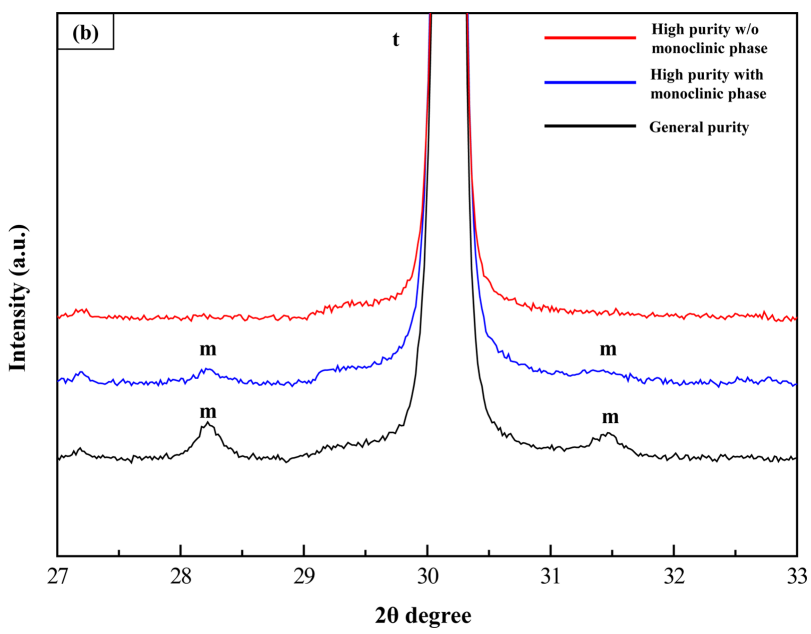

Fig. 8. XRD patterns of top coats before and after FCTF test: (a) before FCTF and (b) after FCTF. 
cyclic thermal fatigue (FCTF) testing. The following conclusions were obtained.

1. For the hardness and porosity changes before and after the FCTF test, the specimens fabricated using high purity YSZ with monoclinic phase and high purity YSZ without monoclinic phase showed an amount of variation that was less than that of the general purity YSZ specimen. Through this result, the excellent sintering resistance of the high purity YSZ powder was determined.

2 . With regard to thermal durability, the microstructure characteristics of a coating layer to make it effective at stress mitigation, or the porosity of the initial coating layer, was found to have a high correlation with the high temperature lifetime, regardless of material impurities.

3. To determine phase stability according to the feedstock powder purity, monoclinic phase was observed for the specimens fabricated using general purity YSZ and high purity YSZ with monoclinic phase both before and after FCTF testing; the diffraction intensity of the monoclinic phase increased after the FCTF test for the specimen fabricated using general purity YSZ. Monoclinic phase was not observed even after the FCTF test for the specimen fabricated using high purity YSZ without monoclinic phase, and the phase stability of high purity YSZ without monoclinic phase was verified.

4. Through this study, it was found that compared to using conventional feedstock powder the application of high purity YSZ powder without monoclinic phase as TBC feedstock powder yields phase stability, thermal durability, and improved sintering resistance when the necessary initial porosity of the coating layer is acquired (general purity YSZ powder).

\section{Acknowledgments}

This work was supported by "Human Resources Program in Energy Technology (No. 20174030201460)" and a "Power Generation \& Electricity Delivery Grant (No. 20181110100310)" of the Korea Institute of Energy Technology Evaluation and Planning (KETEP), granted financial resources by the Ministry of Trade, Industry \& Energy, Republic of Korea, and by a National Research Foundation of Korea (NRF) grant funded by the Korean government (MSIP) (2018R1A5A6075959).

\section{REFERENCES}

1. M. Gell, E. Jordan, K. Vaidyanathan, K. McCarron, B. Barber, Y. H. Sohn, and V. K. Tolpygo, "Bond Strength, Bond Stress and Spallation Mechanisms of Thermal Barrier Coatings," Surf. Coat. Technol., 120 53-60 (1999).

2. R. A. Miller, "Current Status of Thermal Barrier Coatings-an Overview," Surf. Coat. Technol., 30 [1] 1-11 (1987).

3. S. M. Meier and D. K. Gupta, "The Evolution of Thermal Barrier Coatings in Gas Turbine Engine Applications," J. Eng. Gas Turbines Power, 116 [1] 250-57 (1994).

4. D. R. Clarke and C. G. Levi, "Materials Design for the
Next Generation Thermal Barrier Coatings," Annu. Rev. Mater. Res., 33 [1] 383-417 (2003).

5. R. A Miller, "Thermal Barrier Coatings for Aircraft Engines: History and Directions," J. Therm. Spray Technol., 6 [1] 35 (1997).

6. S. Bose and J. DeMasi-Marcin, "Thermal Barrier Coating Experience in Gas Turbine Engines at Pratt \& Whitney," J. Therm. Spray Technol., 6 [1] 99-104 (1997).

7. R. L. Jones, Metallurgical and Ceramic Protective Coatings; pp. 194-235, Chapman and Hall, London, 1996.

8. X. Q. Cao, R. Vassen, and D. Stoever, "Ceramic Materials for Thermal Barrier Coatings,” J. Eur. Ceram. Soc., 24 [1] 1-10 (2004).

9. S. Paul, A. Cipitria, S. A. Tsipas, and T. W. Clyne, "Sintering Characteristics of Plasma Sprayed Zirconia Coatings Containing Different Stabilisers," Surf. Coat. Technol., 203 [8] 1069-74 (2009).

10. A. G. Evans, D. R. Mumm, J. W. Hutchinson, G. H. Meier, and F. S. Pettit, "Mechanisms Controlling the Durability of Thermal Barrier Coatings," Prog. Mater. Sci., 46 [5] 505-53 (2001).

11. D. R. Clarke, M. Oechsner, and N. P. Padture, "ThermalBarrier Coatings for more Efficient Gas-Turbine Engines," MRS Bull., 37 [10] 891-98 (2012).

12. M. N. Rahaman, J. R. Gross, R. E. Dutton, and H. Wang, "Phase Stability, Sintering, and Thermal Conductivity of Plasma-Sprayed $\mathrm{ZrO}_{2}-\mathrm{Gd}_{2} \mathrm{O}_{3}$ Compositions for Potential Thermal Barrier Coating Applications," Acta Mater., 54 [6] 1615-21 (2006).

13. E. Bakan, D. E. Mack, G. Mauer, and R. Vaßen, "Gadolinium Zirconate/YSZ Thermal Barrier Coatings: Plasma Spraying, Microstructure, and Thermal Cycling Behavior," J. Am. Ceram. Soc., 97 [12] 4045-51 (2014).

14. R. Vassen, X. Cao, F. Tietz, D. Basu, and D. Stover, "Zirconates as New Materials for Thermal Barrier Coatings," J. Am. Ceram. Soc., 83 [8] 2023-28 (2000).

15. T. A. Taylor, "Low Thermal Expansion Bondcoats for Thermal Barrier Coatings"; U S Patent 7,910,225 (March $22,2011)$.

16. G. Dwivedi, V. Viswanathan, S. Sampath, A. Shyam, and E. Lara-Curzio, "Fracture Toughness of Plasma-Sprayed Thermal Barrier Ceramics: Influence of Processing, Microstructure, and Thermal Aging," J. Am. Ceram. Soc., 9 [9] 2736-44 (2014).

17. R. Harnacha, P. Fauchais, and F. Nardou, "Influence of Dopant on the Thermal Properties of Two PlasmaSprayed Zirconia Coatings Part I: Relationship between Powder Characteristics and Coating Properties," J. Therm. Spray Technol., 5 [4] 431 (1996).

18. S. Stemmer, J. Vleugels, and O. V. D. Biest, "Grain Boundary Segregation in High-Purity, Yttria-Stabilized Tetragonal Zirconia Polycrystals (Y-TZP)," J. Eur. Ceram. Soc., 18 [11] 1565-70 (1998).

19. K. Y. Park, Y. G. Jung, I. S. Kim, and B. I. Yang, "Effects of Purity and Phase Content of Feedstock Powder on Thermal Durability of Zirconia-Based Thermal Barrier Coatings," J. Therm. Spray Technol., 26 [6] 1161-67 (2017).

20. J. Wang, H. P. Li, and R. Stevens, "Hafnia and Hafnia- 
Toughened Ceramics," J. Mater. Sci., 27 [20] 5397-430 (1992).

21. J. L. Smialek, "Compiled Furnace Cyclic Lives of EB-PVD Thermal Barrier Coatings," Surf. Coat. Technol., 276 318 (2015).

22. C. Wang, Y. Wang, S. Fan, Y. You, L. Wang, C. Yang, X. Sun, and X. Li, "Optimized Functionally Graded $\mathrm{La}_{2} \mathrm{Zr}_{2} \mathrm{O}_{7} /$ 8YSZ Thermal Barrier Coatings Fabricated by Suspension Plasma spraying," J. Alloys Compd., 649 1182-90 (2015).

23]. D. Song, U. Paik, X. Guo, J. Zhang, T. K. Woo, Z. Lu, S. H. Jung, J. H Lee, and Y. G. Jung, "Microstructure Design for Blended Feedstock and its Thermal Durability in Lanthanum Zirconate Based Thermal Barrier Coatings," Surf. Coat. Technol., 308 40-9 (2016).

24]. F. Andreola, C. Leonelli, and M. Romagnoli, "Techniques Used to Determine Porosity," Am. Ceram. Soc. Bull., 79 [7] 49-52 (2000).

25. S. Deshpande, A. Kulkarni, S. Sampath, and H. Herman, "Application of Image Analysis for Characterization of Porosity in Thermal Spray Coatings and Correlation with Small Angle Neutron Scattering," Surf. Coat. Technol., 187 [1] 6-16 (2004).

26. W. R. Chen, X. Wu, B. R. Marple, and P. C. Patnaik, "Oxidation and Crack Nucleation/Growth in an Air-PlasmaSprayed Thermal Barrier Coating with NiCrAlY Bond Coat," Surf. Coat. Technol., 197 109-15 (2005).

27. D. Zhu and A. M. Robert, "Thermal Conductivity and Elastic Modulus Evolution of Thermal Barrier Coatings under High Heat Flux Conditions," J. Therm. Spray Technol., 9 [2] 175-80 (2000).

28. G. Thurn, G. A. Schneider, H. A. Bahr, and F. Aldinger,
"Toughness Anisotropy and Damage Behavior of Plasma Sprayed $\mathrm{ZrO}_{2}$ Thermal Barrier Coatings," Surf. Coat. Technol., 123 [2-3] 147-58 (2000).

29. M. K. Gupta and P. Nylén, "A Modelling Approach to Design of Microstructures in Thermal Barrier Coatings," J. Ceram. Sci. Technol., 4 [2] 85-92 (2013).

30. N. P. Padture, M. Gell, and E. H. Jordan, "Thermal Barrier Coatings for Gas-Turbine Engine Applications," Science, 296 [5566] 280-84 (2002).

31. A. V. Put, D. Oquab, E. Péré, A. Raffaitin, and D. Monceau, "Beneficial Effect of Pt and of Pre-Oxidation on the Oxidation Behaviour of an NiCoCrAlYTa Bond-Coating for Thermal Barrier Coating Systems," Oxid. Met., 75 [56] 247-79 (2011)

32. Y. Li, C. J. Li, Q. Zhang, L. K. Xing, and G. J. Yang, "Effect of Chemical Compositions and Surface Morphologies of MCrAlY Coating on its Isothermal Oxidation Behavior," J. Therm. Spray Technol., 20 [1-2] 121-31 (2011)

33. A. Gil, V. Shemet, R. Vassen, M. Subanovic, J. Toscano, D. Naumenko, L. Singheiser, and W. J. Quadakkers, "Effect of Surface Condition on the Oxidation Behaviour of MCrAlY Coatings," Surf. Coat. Technol., 201 [7] 3824-28 (2006).

34. O. Trunova, T. Beck, R. Herzog, R. W. Steinbrech, and L. Singheiser, "Damage Mechanisms and Lifetime Behavior of Plasma Sprayed Thermal Barrier Coating Systems for Gas Turbines-Part I: Experiments," Surf. Coat. Technol., 202 [20] 5027-32 (2008).

35. R. Stevens, An Introduction to Zirconia; p. 7, Magnesium Elektron Limited, Twickenham, 1983. 